\title{
The impact of the sonic logo's acoustic features on orienting responses, emotions and brand personality transmission
}

\author{
Lluis Mas \\ Department of Communication, Pompeu Fabra University, Barcelona, Spain \\ Paul Bolls \\ College of Media and Communication, Texas Tech University, Lubbock, Texas, USA \\ Emma Rodero \\ Department of Communication, Pompeu Fabra University, Barcelona, Spain \\ Miguel Barreda-Ángeles \\ Department of Communication Science, Vrije Universiteit Amsterdam, The Netherlands, and \\ Ashley Churchill \\ College of Media and Communication, Texas Tech University, Lubbock, Texas, USA
}

\begin{abstract}
Purpose - The purpose of this study is to determine how sonic logo's acoustic features (intensity, pitch and pace) based on melodic tunes with no voice orient the response of consumers, attract attention, elicit levels of pleasantness and calmness and transmit brand personality traits.

Design/methodology/approach - A within-subject experimental factorial design is applied to measure emotional arousal (indexed as electrodermal activity) and enhancement on perceptual processing (indexed as heart rate), as well as self-reported factors, namely, calmness/ excitement, pleasantness and brand personality scales.

Findings - Results show a significant increase on electrodermal activity associated with fast-paced sonic logos and a decrease in heart rate in slow-paced long sonic logos. Also, fade-up, pitch-ascending fast sonic logos are defined as more exciting and descending-pitch sonic logos as more pleasant.

Research limitations/implications - The use of sonic logos with no voice does limit its implications. Besides, the use of three variables simultaneously with 18 versions of sonic logos in a laboratory setting may have driven participants to fatigue; hence, findings should be cautiously applied.

Practical implications - First, sonic logos are best processed in a fade-up form. Second, fast pace is recommended to orient response, whereas slow pace is recommended to transmit calmness. Practitioners may opt for fast-paced sonic logos if the design is new or played in a noisy environment and opt for slow-paced sonic logos in already highly recognized sound designs.

Originality/value - To the best of authors' knowledge, this study is the first to combine psychophysiological measures and self-reported scales in a laboratory experiment on how sonic logo's acoustic features orient response, transmit emotions and personality traits.
\end{abstract}

Keywords Brand personality, Acoustic features, Gestalt theory, Multisensory branding, Orienting response, Sonic logo, Sound branding

Paper type Research paper

\section{Introduction}

One would only need to hear a passing faint hum of the Intel chimes or the "I'm Lovin' it" jingle to imagine the logo, colors and product and to bring ideas on the brand values of these two brands. These short music-based melodies resonate in the minds of most individuals born within the last 50 years in western countries. The Intel sonic logo and the McDonald's sonic logo share a five pitch tones structure with a melodic pattern consisting of an increasing pace and a minor pitch

The current issue and full text archive of this journal is available on Emerald Insight at: https://www.emerald.com/insight/1061-0421.htm

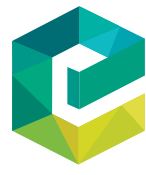

Journal of Product \& Brand Management 30/5 (2021) 740-753

Emerald Publishing Limited [ISSN 1061-0421] [DOI 10.1108/JPBM-05-2019-2370]
(C) Lluis Mas, Paul Bolls, Emma Rodero, Miguel Barreda-Ángeles and Ashley Churchill. Published by Emerald Publishing Limited. This article is published under the Creative Commons Attribution (CC BY 4.0) licence. Anyone may reproduce, distribute, translate and create derivative works of this article (for both commercial and non-commercial purposes), subject to full attribution to the original publication and authors. The full terms of this licence may be seen at http://creativecommons.org/licences/by/4.0/legalcode

This research was supported by the Spanish Government (Jose Castillejo program, Ministerio de Educación, Cultura y Deporte). This institution funded a research stay in the College of Media \& Communication at Texas Tech University. The authors thank both the Spanish Government and Texas Tech University as a host institution.

Declarations of interest: none.

Received 10 May 2019

Revised 4 October 2019

18 February 2020

12 May 2020

10 July 2020

Accepted 12 July 2020 
oscillation in the former and an ascending pitch in the latter. As illustrated by these two examples, sound is arguably a brand asset with great potential for brand recognition and brand values transmission (Ballouli and Heere, 2015; Gustafsson, 2015; Moosmayer and Melan, 2010; Zander, 2006). In the past decades, research on sound branding has increased significantly (Graakjær and Bonde, 2018), including several empirical, experimental or quasi-experimental studies (Gustafsson, 2015; Krishnan et al., 2012; Müller and Kirchgeorg, 2011), yet very few studies have focused on how the acoustic features' variations of sonic logos contribute to some key branding concepts (Rodero and Mas, 2020; Volker and Milton, 2019).

Sound is a critical sensory feature of environmental stimuli that drives how individuals process information through three major acoustic features, namely intensity, pitch and pace. In general, variations of these features can indicate distance and movement between the sound source and the sound receiver (Potter and Bolls, 2012), levels of calmness-excitement (e.g. low-pitched constant sounds vs high-pitched variable sounds) and levels of pleasantness-unpleasantness (e.g. a melodic voice or sound vs high-pitched strident sounds) (Gabrielsson and Lindstrom, 2001). These sound features' properties can be of the highest importance for some branding concepts related to the consumer psychology (Schmitt, 2012) such as brand recognition and brand identity and brand personality through brand values transmission.

The first and foremost contribution of sound to brands is to stand out as a relevant or new signal and to make the brand recognizable to potential customers (Jackson, 2004). For instance, the sound of a lion orients response as a biological avoidance (flight and run away) indicator for humans, especially if this sounds has a fade-up intensity and a fast-paced form (meaning "quick approach"). This immediate unconscious orienting response mechanism is used by MGM's sonic logo to raise attention and recognition and to build an identity. Subsequently, the MGM's sound can consciously be associated with such values as powerfulness, hierarchy or immediate threat. Although research on acoustic features and brand personality is scarce, there are solid evidences on how voice pitch variations transmit physical characteristics, personality traits and sensations (Lehmann, 2008; Rodero and Larrea, 2021). As put by Rodero and Larrea, "if the brand wants to transmit energy, freshness, optimism, or amusement, a higher-pitched voice is recommended" (2021, p. 73). Besides, some authors have established a connection between musical sonic logos and brand personality (Müller and Kirchgeorg, 2010). And Lowe et al. (2019) found that loud and low-pitched strident sounds are associated with anxiety and lead to risk avoidance behaviors in marketing such as spending more on car insurance or selecting food with lower taste uncertainty. So, variations in sound intensity, pitch and pace may also facilitate the processing of values and personality traits and the consumer behavior.

The objective of this study is to investigate how these three acoustic features (intensity, pitch and pace) of sonic logos can elicit attention and raise emotional responses (calmnessexcitement and pleasantness-unpleasantness), increase brand recognition, facilitate processing and transmit brand personality. This study applies an experimental design with psychophysiological measures, self-reported scales on emotions and a brand personality scale. Findings point to directions for future studies and provide insight into the effects and potential use for practice of these acoustic features in the sound branding field.

\section{Theoretical framework}

\section{Media psychology and sound processing}

Research on the basic mechanisms of motivated behavior suggests that responses to environmental stimuli are broadly organized around two motivational systems: the appetitive system and the avoidance system (Bradley, 2009; Lang, 2009). These systems function by making humans approach (have an appetite for) positive stimuli and avoid (have an aversion for) negative stimuli. These two systems are activated by an orienting response, which is a "what is it" reflex that can be conceptualized as a momentary increase of attention (Lang, 2009). Two key facets of the orienting response are increased physiological arousal (related to preparation for action) and heightened perceptual processing (i.e. higher intake of information from the stimulus) (Bradley, 2009). The application of cognitive sciences to the study of media information processing is explained and theorized by the media psychology field.

Media psychology has proven fruitful for the study of the effects of sound elements and acoustic features of media messages on recipients' attention and processing capabilities. While previous research in media psychology has thoroughly examined how the auditory components of media messages voices, effects, silence, noise and music - affect overall orienting responses (Bolls, 2013; Bolls and Lang, 2003; Dillman Carpentier and Potter, 2007; Potter et al., 2008; Potter et al., 2015; Rodero, 2019a, 2019b), the acoustic features of these components - pitch, melody, intensity, duration and pace, among others - have hardly been investigated (Rodero and Mas, 2020; Rodero, 2015), especially not as part of a brand or a sonic logo.

There are some exploratory attempts to explain how more general sound-patterns may elicit perceptual and processing responses. According to the reduced articulation form (RAF) concept defined by Bonde and Hansen (2013), the more a sound articulation complexity is reduced, the higher the level of perceptual abstraction. The RAF mechanism aligns with the rationale of Gestalt Theory if applied to sound processing and perception (Leder et al., 2004; North et al., 2004), according to which humans are biologically prepared to perceive meaningful units as a result of using criteria such as order, symmetry or contrast to the processing of different sound elements and acoustic features variations. This is a perceptual and cultural mechanism used to find continuities in the auditory stimuli (Winkler et al., 2009, p. 532). For instance, Reber et al. (2004) characterize (western) music with principles such as symmetry, clarity, goodness-of-form, proportion, balance and harmony. The tendency to find regularities in the sound - e.g. a synchronous increase in pitch, intensity and pace - orients response and influences the perception of pleasantness, attitudes and behavior (Rodero, 2015). 


\section{Sound branding}

Sound branding is the strategic use of sound to communicate the identity and values of a brand in the different touchpoints with its publics (Groves, 2009; Krishnan et al., 2012). A sonic logo can be defined as "the auditory analog of a visual logo" (Krishnan et al., 2012, p. 276). The main role attributed to sonic logos is to associate the brand with sounds or with acoustic features so that the brand can be recognized immediately (Bonde and Hansen, 2013; Jackson, 2004) and, arguably, transmit emotions and brand values. Sonic logos usually have a duration between 2 and $6 \mathrm{~s}$ (Bonde and Hansen, 2013) and can have different degrees of musical complexity, be based on noises and sound effects or contain verbal or nonverbal elements. Sonic logos are part of the Sound Branding field (Jackson, 2004).

Studies on sound branding try to associate independent variables such as "musical pace, pitch, mode, genre, fit, familiarity and liking" and dependent variables such as "awareness, recall, attitudes, evaluation, behavioral intent and behavior" (Graakjær and Bonde, 2018, p. 1506; see also Ballouli and Heere, 2015) in different sound objects. Some of the most relevant studies in this field have focused on the phonemic significance of brand names (Davis et al., 2016; Klink, 2000; Pathak et al., 2020), background music in shopping settings (Biswas et al., 2019; Lowe et al., 2019), the sound of products' properties (Lowe and Haws, 2017), sound designs for specific products (Zampini and Spence, 2005) and the sound of brands in general (Rodero et al., 2013) . Music is a particularly relevant stimulus that can prompt emotions and enhance memory in advertising (Alpert et al., 2005; Dubé et al., 1995; Lantos and Craton, 2012), as well as transmit values such as modernity by playing pop music (as opposed to classical) in real-life store contexts (Müller and Kirchgeorg, 2011). However, very few studies have examined the contribution of sound to the orienting response to sonic logos or the transmission of brand constructs such as brand personality.

\section{Hypotheses and research questions development}

There is evidence suggesting that variation in intensity, pitch and pace may activate the appetitive and aversive motivational systems and elicit orienting responses. Specifically, we propose here that the intensity, pitch and pacing of the musical notes used in a sonic logo create sensory perceptions of relevance, newness, distance and movement (moving toward/moving away; moving up/moving down and speed of movement). These perceptions should evoke orienting responses to the sonic logo that reflect the motivational significance of variation:

RQ1. How do the variations of intensity, pitch and pace in a sonic logo affect the physiological arousal and information intake involved in the orienting response?

\section{Effect of sonic logo's intensity variations on orienting responses}

The increasing loudness of a sound may indicate that the source is approaching, thus the proper processing of this phenomenon has direct consequences to survival. It seems plausible that the motivational systems have evolved to be more activated with increasing intensity than with decreasing intensity of perceived sounds. Indeed, increasing sound intensity may be seen as a "warning cue" that recruits attentional and physiological resources in the brain (Bach et al., 2007). Research in the field of music has evidenced that higher music intensity is related to increased physiological arousal as indexed by electrodermal activity (EDA), as well as to cardiac patterns related to orienting responses (Chuen et al., 2016; Gomez and Danuser, 2007). We argue that those effects, observed with music, may also be applied to sonic logos. We, therefore, predict the following:

H1. Sonic logos with ascending intensity (musical notes fading up) will evoke stronger orienting responses than sonic logos with descending intensity (musical notes fading down). This will be evidenced in the following:

H1.1. Higher values of EDA.

H1.2. Lower values of heart rate (HR) following the sonic logo.

\section{Effect of sonic logo's pitch variations on orienting responses}

Pitch is one of the most important features to raise attention as found in a long tradition of human processing and perception research in both verbal and nonverbal communication (grounded in different disciplines such as linguistics, psycholinguistics, communication or even engineering). Pitch configures an attentional structure in media messages and is thus used to mark stress (Mas Manchón, 2011; Potter, 2006; Rodero, 2015).

The effects of pitch on motivational activation could be because of evolutionary reasons, as emotional calls and threat signals are usually characterized by a high pitch (Buss, 2008; Patel, 2010). Compared to descending pitch, ascending pitch in music is more commonly related to emotions such as surprise, anger or fear (Gabrielsson and Lindstrom, 2001). Previous research on the psychological responses to musical features has shown that both increases in EDA (Kallinen and Ravaja, 2003) and patterns corresponding to cardiac orienting responses are associated with ascending pitch (Chuen et al., 2016). Thus, we predict that pitch variations of sonic logos will elicit orienting responses, specifically, that hypothesize:

H2. Sonic logos with ascending pitch will evoke stronger orienting responses than sonic logos with descending pitch. This will be evidenced in the following:

H2.1. Higher values of EDA.

H2.2. Lower values of HR following the sonic logo.

\section{Effect of sonic logo's pace variations on orienting responses}

Regarding pace, there also are evolutionary reasons to expect a higher motivational activation toward stimuli with a higher pace in comparison to a slower pace, as it may represent a faster movement (e.g. from a source that may represent a threat) than a sound with a slower pace. In the domain of music, pace is a critical feature, strongly connected with motivation and the 
transmission of emotions (Bispham, 2009; Zentner et al., 2008). Typically, high-paced music relates to high arousal, and is perceived as more exciting and dynamic, whereas slowpaced music is associated with low arousal, calm and less active messages (Dillman Carpentier and Potter, 2007). Furthermore, variations on EDA and HR have been connected with increases in music pace (Chuen et al., 2016; Khalfa et al., 2008; Kim et al., 2019; van der Zwaag et al., 2011). Hence, we hypothesize the following:

H3. Fast-paced sonic logos will evoke stronger orienting responses than slow-paced sonic logos. This will be evidenced in the following:

H3.1. Higher values of EDA.

H3.2. Lower values of HR following the sonic logo.

\section{Effect of sonic logo's features variations on brand} recognition and reported calmness and pleasantness

Bonde and Hansen (2013) tested different sonic logos and found that the musical pattern of them, which is the melody created by a sequence of pitch levels (such as the case of the Intel and McDonald's sonic logos), is the most important property to make a sonic logo identifiable, recognizable and perceived as calm and pleasant. Following this rationale, the figure (or shape/form) of music is given by a melody (pitch variation) within a background sound context (Leder et al., 2004). Intensity and pitch are perceptually connected according to the alignment or coherency of multisensory communication. Given this, regularity, symmetry and continuity are some of the Gestalt Theory's laws that would imply matching directions (positive correlations) between acoustic features (fade up, ascending pitch and fast pace vs fade down, descending and slow pace or no variations - constant) to raise brand recognition and recall (Bonde and Hansen, 2013; Reber et al., 2004). These theoretical grounds have not been empirically tested before in relation to sonic logos, so the following has been hypothesized:

RQ2. What type of covariations of intensity, pitch and pace in a sonic logo increases brand recognition and is perceived as more calm (vs excitement) and more pleasant (vs unpleasant)?

\section{Effect of sonic logo's features variations on Brand personality}

The musical pattern rationale used to improve brand attitudes and brand values transmission may lead to the transmission of brand personality traits. Sound features of voices have been formerly associated with personality traits (e.g. high-pitched voices are associated with girlish, immature, tender or weak and low-pitched voices with dominance, power, warm, attractiveness [...]) (Rodero et al., 2013). Analogously, Müller and Kirchgeorg (2010) proposed a model that systematically associates a brand's big five personality traits with a wide spectrum of music features focusing on music genres (mainly defined by instruments, timbre, pace, pitch, harmony and melody). To name the most relevant associations, excitement is associated with high-pitched fast music genres, ruggedness is associated with slow and low-pitched and sophistication with strings and classical music. In addition, activity can be easily associated to the movement indicated by intensity and pitch variations. In general, excitement, ruggedness, sophistication, activity or simplicity or emotionality are dimensions of Aaker's brand personality scale (1997; Geuens et al., 2009), yet, no prior studies on brand personality have focused on isolating specific sound features and connecting them with brand personality traits in experimental settings. This study aims to fill this gap:

RQ3. What are the brand personality traits associated with the sonic logo's acoustic features (sonic logo's intensity, pitch and pace variations)?

\section{Methods}

\section{Stimuli}

This experiment consists of a 3 (intensity: fade up, fade down and constant) $\times 3$ (pitch: ascending, descending and constant) $\times 2$ (pace: fast and slow) within-subjects factorial design. A withinsubjects design is used because it gives an acceptable statistical power with fewer participants than in a between-subjects design. This is important when applying a costly and time-consuming laboratory experiment with psychophysiological measures.

The three independent variables were crossed to create 18 experimental versions of the sonic logo (stimuli). Each sonic logo was professionally produced; these sonic logos had a 3-s duration (Bonde and Hansen, 2013), 5 notes (Krishnan et al., 2012), 1 octave pitch range, $30 \mathrm{~dB}$ variations, $3 / 4$ and $4 / 4$ pace, upper tonality $\mathrm{C}$, with a low-pitched techno instrumentation. The 18 versions of the sonic logo were produced by a music designer in a southwestern city in the USA (Figure 1).

The 18 versions of the sonic logo are placed at the beginning of a $9 \mathrm{~s}$ voice message. This message was spoken by two male presenters from the KTXT-FM (88.1 FM), a non-commercial radio station licensed to the university where the study was conducted; one speaker was voicing the brand name $(130 \mathrm{~Hz}$ average pitch) and the other the message $(110 \mathrm{~Hz}$ average pitch). The brands were 18 real but unknown brands (with no sound or written meaning in English) (ABA. Audio Branding Academy, 2017): HRS, WAZ, Dachser, Grünenthal, Drei, Friis, Ybarra, Mahle, Sabesp, DTS, Verbund, Mümax, Gefco, Dea, Nordsee, Veltins, Ströck and Afoma. A familiarity test was run to guarantee lack of previous awareness. Data indicate that the 18 target brands were not identified as they scored between 1 and 1.40 in the familiarity test (from 1 - I have never heard of the brand- to 9 - I love this brand), except for HRS which scored 2.65. Although this last score is considerably higher than the rest of the target brands, it is still much lower than the scores of the 11 known control brands (Oberstaufen, British Airways, Trivago, Electronic Arts, Sony, Canal+, NBC, RTL, Twentieth Century Fox, Lexus, Verti, Mercedes, Green Flag, KTM, Targo Bank, easyCredit, Direct Line, Chevron, Intel, Olympus, Coca-Cola, Apollinaris, Haribo, Mister Donut, Yakult, Audi, Marché, Brand24, Würth International, Nivea and Bauhaus), which scored between 4 and 7-8 in this test. Overall, this familiarity test guarantees that the results will not be because of the artifact of the awareness of the brand name. 
Figure 1 Sonic logo
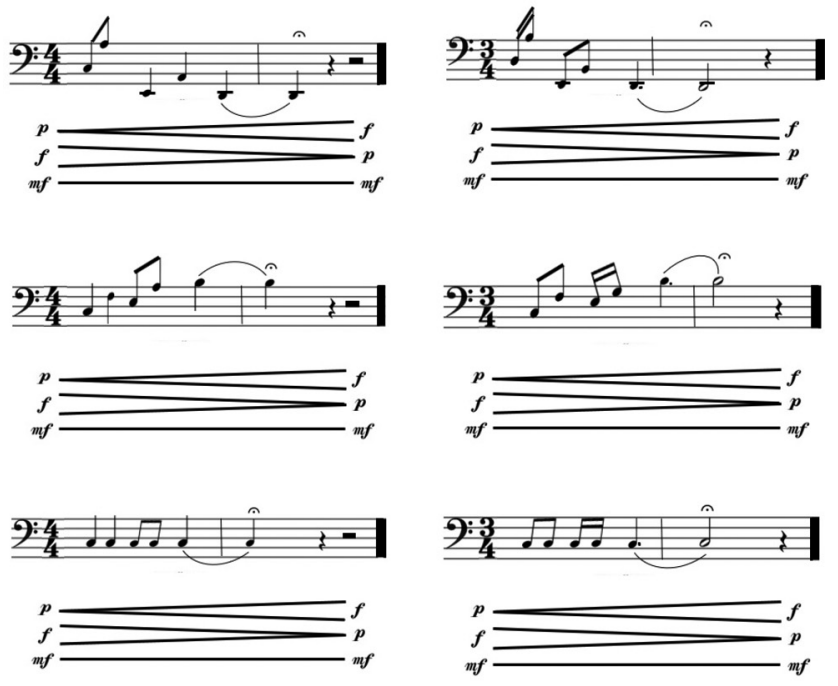

Notes: Versions 1-18; 1-3 (first staves and first-row top): descending pitch/slow pace (fade up, fade down and constant intensity); 4-6 (second staves and second-row top): descending pitch/fast pace (fade up, fade down and constant intensity); 7-9 (third staves, first-row middle): ascending pitch/slow pace (fade up, fade down and constant intensity); 10-12 (fourth staves and second-row middle): ascending pitch/fast pace (fade up, fade down and constant intensity); 13-15 (fifth staves and first-row bottom): constant pitch/slow pace (fade up, fade down and constant intensity); and 16-18 (sixth staves and second-row bottom): constant pitch/fast pace (fade up, fade down and constant intensity).

Thus, the 18 versions of the sonic logo were embedded in a sound-based bumper ad with the following structure: sonic logo, brand name and a voice announcement. The template for the announcement voiced after the sonic logo and brand name is as follows: call to action (Get ready/Gear up/Listen up), discount (Get a 5\%/25\%/50\% off), time of the offer (today/this week/this month), brand name and final claim (Made for you/Created for you/Designed for you, Since 1992/1994/1996). The announcement showed different combinations of this information to recreate a realistic commercial break with 18 different messages, although with the same structure and amount of information. Therefore, the brand name is mentioned twice in the sound message, once after sonic logo and once more within the announcement. Bumper ads are 5-7 s un-skippable YouTube or Facebook ads. Here we test an experimental sound that could be used in scenarios of multitasking both online such as music platforms and offline such as in a gas station while pumping gas.

Moreover, the placement of the logo at the beginning of the ad is a relatively recent practice in campaigns in all media, including TV, as shown in $2017 \mathrm{~T}$-Mobile and Netflix ads in the USA, and in YouTube videos or podcasts in general. Although this is becoming a common practice in the profession, to our knowledge, no previous studies have examined the effects of these phenomena. As the sonic logo was the first element of the sound message, the physiological measures could not be affected by the announcement information.

These 18 sonic-logo versions were randomized in three conditions. To guard the study from artifacts, the 18 brand names and 18 versions of the announcement were randomized in each condition. This entails that each independent variable variation (fade up, fade down and constant intensity; ascending, descending and constant pitch; and fast and slow pace) was presented six (intensity and pitch) and nine (pace) times with a different brand name and announcement information to cancel out the effects of this information. Thus, the self-report responses of participants could not be attributed to differences in brand names or announcements. For instance, consistent results on sonic logos with ascending pitch cannot be attributed to the brand name or announcement, which is different in the six sound messages with ascending pitch.

In sum, each condition contained the exact same 18 versions of sonic logo, as well as the exact same 18 brand names and the exact same 18 versions of the announcement. However, the three elements were randomized in each of the three conditions, so that the potential artifacts of the brand names and announcements canceled out. This also allowed us to measure the consistency of responses to the same acoustic features' variations across the three conditions and measure the significance between different acoustic features' variations.

\section{Participants and procedure}

Each participant was exposed to one of three conditions (16 participants in Condition 1, 16 in Condition 2 and 17 in Condition 3). The three conditions had the same acoustic features' variations, so that all participants were exposed to the same 18 experimental versions, thus keeping the within-subjects design. Participants in this study $(N=49)$ were undergraduate students enrolled at a southwestern university who received course credit in exchange for participating in the study. Participants were recruited via the SONA system (a well-known platform in colleges for students to enroll in studies) between October 14 and October 28 in 2017. The participants' age was limited to 19-22 years. The mean age was 19.14 years (standard deviation $[\mathrm{SD}]=1.976$ ), $26.2 \%$ were men. This study has prioritized having a homogenous group of participants over other targeting criteria.

Participants completed the experiment individually in a laboratory designed for the collection of physiological measures. Participants were welcomed by two researchers (the first author was always one of these), were thanked and were given a consent form (as approved by the Ethical Committee of the university). They were informed that the study aimed to measure some of their reactions and that they had the right to quit the experiment any time. If they understood the form and could agree with it, they were asked to sign it. After signing the consent form, they were asked to wash their hands in the bathroom. Then the participant sat in the chair in the experimental room while we explained the procedure and wiped down some areas of the forearms with alcohol pads (asking if they had any sensitivity to alcohol), removing any electronics or metal gadgets of this participant and putting two sensors in the palm of the left hand, as well as on the wrist and the two forearms (ground, positive and negative connection). Then a table was placed over the chair to provide access to the keyboard and mouse. The participant was asked not to 
move much during the study and was told that he/she could quit the experiment anytime by raising a hand. She/he was given the instructions that she/he would have to respond to questions about some brands, then hear several audio messages and answer some questions, most of which were multiplechoice. We explained that the process was very easy and that the instructions would appear at the top of the screen. After a distractor task consisting of viewing a music video to clear out short-term memory, participants were asked to complete a brand recognition test. The entire task took an average of $35 \mathrm{~min}$. Once the study was complete, we disconnected all sensors, thanked the participant and asked him/her not to disclose any information about this study to anyone. The participant was kindly dismissed.

\section{Measures}

$E D A$ and $H R$. The orienting response is a psychological construct that cannot be directly measured but can be observed through their physical manifestations. In this regard, EDA has been commonly considered as a proxy of the increased physiological arousal associated with the orienting response, while variation in $\mathrm{HR}$ has been shown to be indicative of increased information intake (Bradley, 2009). EDA refers to the conductivity of the skin, which is affected by the activity of the eccrine sweat glands. The physiological arousal related to the orienting response involves increased activity of the sympathetic nervous system, which stimulates the production of sweat by the eccrine sweat glands, thus increasing the conductivity of the skin (Dawson et al., 2007). Therefore, variation in EDA is seen as an indicator of the physiological arousal/action preparation component of the orienting response (Bradley, 2009). In turn, the orienting response also leads to enhanced activity of the parasympathetic nervous system, which decelerates HR (Bradley, 2009). Hence, temporary deceleration of $\mathrm{HR}$ is indicative of the enhanced information intake aspect of the orienting response (Bradley, 2009). EDA and HR were thus collected as physiological indicators of the orienting response. These data were recorded time locked to the presentation of each sonic logo. EDA was collected by placing silver-silver chloride electrodes on the thenar and hypothenar eminences of the hand, whereas HR was collected by placing silver-silver chloride electrodes on the forearm. Both signals were collected with a sampling rate of $1000 \mathrm{~Hz}$, using a BIOPAC ${ }^{\mathrm{TM}}$ MP150 system (BIOPAC Systems Inc., Santa Barbara, CA, USA).

Brand recognition. This measure was tested through a speed recognition test. This test consisted of 18 targets and 18 foils. A professional announcer was recorded reading the names of the targets and foils and they were played back for the participants. Participants were instructed to press keys corresponding to "yes" or "no" to indicate whether the brand name was from one of the announcements they had heard during the session.

Self-reported emotion (calmness/excitement) and level of pleasantness or unpleasantness. These two measures used a nine-point scale. Participants were specifically asked to indicate how exciting or calm and pleasant or unpleasant, they perceived each sonic logo and announcement to be. These measures are based on the dimensional theory of emotion and are frequently used to complement and compare psychophysiological measures of emotional valence and emotion intensity to self-reported emotion experience (Bradley and Lang, 2007).

Brand personality. Aaker's dimensions were redefined in a study with different types of brands - functional, image, experiential and hedonic brands (Geuens et al., 2009). This model renames the dimensions although it applies some common personality traits: dimension responsibility (down-toearth, stable and responsible), dimension activity (active, dynamic and innovative), dimension aggressiveness (aggressive and bold), dimension simplicity (ordinary and simple) and dimension emotionality (romantic and sentimental). Geuens et al.'s 12 traits are randomized in a seven-point Likert Scale from 1 (not characteristic for the brand) to 7 (very characteristic for the brand).

Statistical analysis. The analysis of psychophysiological data is explained in the next section. Regarding the selfreported measures, a chi-square test is applied to the analysis of brand recognition; Cronbach's alpha is applied to test the reliability of brand personality; and one-way analysis of variance (ANOVA) and Student's $t$-test are applied to show significant differences between the self-reported scales.

\section{Psychophysiological data filtering and analysis}

To ensure the quality of the psychophysiological recordings, they were plotted and visually inspected by a researcher with experience in the analysis of psychophysiological signals. The EDA recordings from nine participants, and the HR recordings from 11 participants presented clearly noisy signals (likely owing to partial electrode detachment or participant's movements) and were excluded from the analysis. Moreover, EDA signals of eight messages from five participants, and HR signals of other eight messages from four different participants were also considered as noisy and not included in the analysis. Thus, the final sample of EDA signals includes the recordings of 732 messages from 41 participants, whereas the final sample of HR signals includes the recordings of 694 messages viewed by 39 participants.

For both EDA and HR, the signal corresponding to $5 \mathrm{~s}$ after the delivery of the brand name was selected and downsampled to $1 \mathrm{~Hz}$, thus obtaining a temporal series of five values for each message and participant. Then the value of the baseline (calculated as the mean value in the $5 \mathrm{~s}$ immediately before the sonic logo) was subtracted to each value of the temporal series. Data for each psychophysiological measure (EDA and HR) in each message and participant consist of a baseline-corrected temporal series of $5 \mathrm{~s}$.

The statistical analysis was based on the use of multilevel mixed models (Bliese, 2016; Kristjansson et al., 2007; PageGould, 2017). The process is similar to a stepwise regression, in which successive models of the data, progressively including more predictors, are fitted and compared to models with a lower number of predictors using likelihood tests, to assess how each predictor improves model fitting to data (Bliese, 2016). The first steps in these processes were to include a random intercept for participants, and an autocorrelation function for handling the high autocorrelation usually present in temporal series of psychophysiological measures. Then the effects of time within each message were also tested, by including the relative time within the stimulus as both a fixed and a random term. 
Following this, the order of presentation and the experimental condition were also included in the model. In each of these steps, a likelihood test (Bliese, 2016) was conducted to check whether each factor improved model fitting compared to the previous model without that factor; and the factor was only preserved in successive steps if it significantly improved model fitting. Thus, this process allowed to control for the effects of these variables before testing the effects of the independent variables in the study. Finally, the independent variables, intensity, pitch and pace, were included in the model in just one step to examine whether the coefficients associated with each variable were statistically significant.

\section{Results}

\section{Psychophysiological measures}

$R Q 1$ inquired about the effects of variation in intensity, pitch and pace in a sonic logo on the physiological arousal and information intake involved in the orienting response. The method applied to answer this question involved the examination of the main effects of the variables (as stated in our hypotheses) and the interactions between them. Regarding the main effects, as summarized in Table 1, fadedown intensity was associated to a significant increase on EDA, whereas no significant effects were found for fade-up intensity, and no significant effects on neither fade up nor fade-down intensity over HR were observable. Our first hypothesis predicted an effect of intensity over the orienting response (H1.1), which would be evidenced by higher and lower levels of EDA for fade-up and fade-down intensity, respectively. The only significant effect found (increased EDA related to fade-down intensity) is in the opposite direction than expected; therefore, H1.1 was not supported.

Table 1 Coefficients for the final models for EDA and HR

\begin{tabular}{lcc}
\hline Fixed factors & EDA & HR \\
\hline Intercept & $0.16^{* *}$ & $-3.17^{* * *}$ \\
Intensity & & \\
Fade-up & -0.02 & 0.43 \\
Fade-down & $0.12^{* * *}$ & 0.11 \\
Pitch & & \\
Ascending & -0.02 & 0.51 \\
Descending & 0.01 & -0.02 \\
Pace & & \\
Fast & -0.1 & $-0.64^{*}$ \\
Time & $-0.02^{* *}$ & \\
Random factors & & \\
Intercept & 0.21 & 2.04 \\
Time & 0.03 & 0.40 \\
Residuals & 0.76 & 6.77 \\
-2Loglikelihood & $4,267.84$ & 0.61 \\
Phi estimate & 0.83 &
\end{tabular}

Notes: Coefficients for the fixed factors for the EDA and HR models are expressed, respectively, in $\mu S$ and beats-per-minute. Coefficients for the random factors are expressed in SD. For the variables intensity, pitch and pace, the baseline levels are, respectively, the levels constant, constant and slow, against which the other levels are compared; ${ }^{*} p<0.05$; ${ }^{* *} p<$ $0.01 ;{ }^{* * *} p<0.001$
Furthermore, as no significant effects of intensity were found on HR, H1.2 was not supported either.

Regarding pitch, our second hypothesis predicted an effect of ascending pitch over the orienting response, which would manifest as an increase in EDA (H2.1) and a decrease in HR (H2.2) after the sonic logo. As no significant effects of the pitch were observed for none of the two psychophysiological measures, neither $H 2.1$ nor $H 2.2$ found support. Third, we also predicted that faster pace would elicit stronger orienting responses, involving (H3.1) higher EDA values as well as (H3.2) lower HR values. The significant decrease of HR associated with a fast pace (Table 1) provides support for H3.2, whereas $H 3.1$ was not supported.

Additionally, the data show a fixed effect of time within the stimuli, according to which EDA gradually decreased over time within the duration of each message.

When interaction between the variables were added, the models showed clear signs of overfitting (Babyak, 2004; Yarkoni and Westfall, 2017). These include a variety of significant effects of the variables, with different sign in the main and interaction effects, together with low values of adjusted- $R^{2}$. As it seems likely that the overfitting occurred when adding the interactions between the variables, the results of the analyses of interactions between sonic logo features over EDA and HR cannot be trusted. Therefore, the results do not allow us to clearly explain how acoustic features of intensity, pitch and pace in a sonic logo interact in evoking the orienting response. As will be discussed in the next section, only fastpaced sonic logos could be associated with orienting response.

\section{Brand recognition and self-reported emotion and brand personality}

We now focus on the results of self-reported measures brand recognition, emotion (calmness/excitement), level of pleasantness or unpleasantness and brand personality, elicited by the independent variations of the sonic logo. Some previous tests are applied to assess the reliability of measures. A one-way ANOVA is applied to the messages gathered by the type of offer $(5 \% / 25 \% / 50 \%)$ to control this variable and make sure that no artifacts intervene in the results. Levene's homogeneity of variance test was statistically non-significant for all selfreported items (with $p$ clearly over 0.05 ). Tukey's post hoc test is applied and confirms that there were no significant differences between brand recognition, emotion, pleasantness and brand personality, among the messages with $5 \%, 25 \%$ or $50 \%$ offers. Regarding brand recognition, as the responses were nominal (yes-no), a chi-square test was applied to see effects of the acoustic features on brand recognition. No significance was found $(p>0.05)$, which shall be discussed as a methodological limitation of the study.

Further, two reliability tests are applied to brand personality. First, Cronbach's alpha is applied to the brand personality scale, resulting in 0.720, which indicates a high level of reliability. Second, the factorability of the 12 items was examined. The Kaiser-Meyer-Olkin value was 0.795, exceeding the recommended value of 0.6, and Bartlett's Test of Sphericity reached statistical significance. The communalities were all above 0.3, confirming that each item shared some common variance with other items. Given these overall indicators, factor analysis was deemed to be suitable with all 12 
items. All items of the scale were factor analyzed using principal component analysis with Varimax (orthogonal) rotation. Factor analysis produced three stable factors explaining a total of $61.129 \%$ of the variance for the entire set of variables. Factor 1 had high loadings by the following items: innovative, bold, active, aggressive and dynamic. This factor explained $26.894 \%$ of the variance. Factor 2 had high loadings by the following items: responsible, simple, ordinary, stable and explained $23.224 \%$ of the variance. Factor 3 explained $11.001 \%$ of the variance and had high loadings, over 0.5 , by the following items: romantic, down to earth and sentimental. We called factor 1 "energy", factor 2 "balance" and factor 3 "emotion". Cronbach's alpha showed to reach acceptable reliability in all the scales: Factor 1, $\alpha=0.782$, Factor $2, \alpha=0.787$ and Factor 3, Cronbach's alpha, $\alpha=0.716$. To test the statistical significance of the self-reported measures, a one-way ANOVA was applied to intensity (three variations: fade up, fade down and constant), to pitch (three variations: ascending, descending and constant), to pace (two variations: fast, slow) and to the three variables' covariations (either increasing, named here arousing, or decreasing, named here non-arousing). There were no significant results for intensity, arousing, pitch and pace in any of three composites (Table 2). Therefore, no conclusions can be drawn regarding Geuens et al.'s five dimensions or the factor's analysis of the new three dimensions.

A one-way ANOVA is applied to the self-reported emotion (calmness/excitement) and level of pleasantness or unpleasantness. Firstly, with regard to intensity, Levene's homogeneity of variance test was statistically non-significant for the two items (calmness/excitement, $p=0.207$; pleasantness, $p=0.820$ ) making it possible to assume that the variances were the same and fell in line with the principle of homoscedasticity. The one-way ANOVA shows significant effects for

Table 2 One-way ANOVA of intensity, arousing, pitch and pace for the three new factors of brand personality

\begin{tabular}{lcccccc}
\hline Acoustic & Energy & & Balance & & Emotion \\
features & $\boldsymbol{F ( 1 , 8 8 0 )}$ & $\boldsymbol{p}$ & $\boldsymbol{F ( 1 , 8 8 0 )}$ & $\boldsymbol{p}$ & $\boldsymbol{F ( 1 , 8 8 0 )}$ & $\boldsymbol{p}$ \\
\hline Intensity & 1,753 & 0.186 & 0.21 & 0.884 & 0.267 & 0.605 \\
Arousing & 0.097 & 0.755 & 1627 & 0.202 & 0.094 & 0.325 \\
Pitch & 0.110 & 0.740 & 0.053 & 0.818 & 0.318 & 0.573 \\
Pace & 0.006 & 0.938 & 0.527 & 0.468 & 0.058 & 0.809 \\
\hline
\end{tabular}

pleasantness [calmness/excitement, $F(2,879)=1.596, p=$ 0.203; pleasantness: $F(2,879)=3.075, p<0.05]$. As variance between groups was the same for pleasantness, Tukey's post hoc test is applied. This test confirms that fade-up sonic logos are significantly $(p<0.05)$ more pleasant $(M=5.34)$ than fadedown sonic logos $(M=4.93)$ and constant intensity sonic logos $(M=5.17)(F(2,879)=3.075, p<0.05)$. Dunnett's T3 test did not show significant results for calmness/excitement.

Regarding pitch, Levene's homogeneity of variance test was statistically non-significant for the two variables. The one-way ANOVA shows significant effects for variable calmness/ excitement $[F(2,879)=3.810, p=0.023]$; and no significant effects for pleasantness $[F(2,879)=2.253, p=0.106]$. Dunnett's T3 is applied to calmness/excitement and Tukey's post hoc test is applied to pleasantness. Results show a significant effect $(p<0.05)$ for pleasantness between descending pitch $(M=5.30)$, ascending pitch sonic logos $(M=5.21)$ and constant pitch sonic $\operatorname{logos}(M=4.96)$ and for calmness/excitement between ascending pitch $(M=3.03)$ and constant pitch $(M=3.49)$. In sum, descending pitch sonic logos are slightly (but significantly) more pleasant, and constant pitch sonic logos are calmer.

A Student's $t$-test is applied to the two binomial fast vs slow versions of sonic logo and arousing vs non-arousing version of sonic logo. As for the first, Levene's homogeneity of variance test was statistically non-significant for calmness/excitement $(p=0.660)$ and significant for pleasantness $(p=0.020)$. The $t$-test significance is thus applied, but no significant results are obtained $(p>0.05)$ (see Table 3 for the means and SDs). As can be seen, fastpaced sonic logos scored higher in the calmness/excitement scale $(M=3.34$ fast-paced, $M=3.15$ slow-paced).

Regarding the arousal or non-arousal of the sonic logo versions, the Student's $t$-test is also applied. First, Levene's homogeneity of variance test was statistically non-significant for pleasantness $(p=0.852)$ and significant for calmness/ excitement $(p=0.010)$. The $t$-test is thus applied to pleasantness $(t(190)=2.327, p<0.05)$ and to calmness/ excitement $(t(291)=-2.144, p<0.05)$. Therefore, differences between arousing versions and non-arousing are significant for both the level of excitement $(M=2.88$ for arousing and $M=$ 3.43 for non-arousing) and pleasantness $(M=5.41$ for arousing and $M=4.83$ for non-arousing).

Table 3 One-way ANOVA on intensity and pitch variations; and student's $t$-test on pace variations and the binomial arousing/non-arousing

\begin{tabular}{|c|c|c|c|c|c|c|}
\hline Dependent variables & $M$ Intens. fade up & $M$ Intens. fade down & $M$ Intens. constant & SD & $F$ & $p$ \\
\hline Excitement & 3.35 & 3.32 & 3.07 & $2.1 / 2 / 2.15$ & 1.596 & 0.203 \\
\hline \multirow[t]{2}{*}{ Pleasantness } & 4.93 & 5.17 & 5.34 & 2/2/1.97 & 3.075 & 0.047 \\
\hline & $M$ pitch ascending & $M$ pitch descending & $M$ pitch constant & SD & $F$ & $p$ \\
\hline Excitement & 3.03 & 3.18 & 3.49 & $2 / 2.1 / 2.14$ & 3.810 & 0.23 \\
\hline \multirow[t]{2}{*}{ Pleasantness } & 5.21 & 5.30 & 4.96 & $2.06 / 2 / 1.9$ & 2.253 & 0.106 \\
\hline & $M$ fast & $M$ slow & - & SD & $F$ & $p$ \\
\hline Excitement & 3.34 & 3.15 & - & $2 / 2.1$ & 1.784 & 0.182 \\
\hline \multirow[t]{2}{*}{ Pleasantness } & 5.12 & 5.19 & - & $2.1 / 1.9$ & 0.308 & 0.579 \\
\hline & $M$ arousing & $M$ non-arousing & - & SD & $F$ & $p$ \\
\hline Excitement & 2.88 & 3.29 & - & $2.11 / 1.9$ & 3.325 & 0.069 \\
\hline Pleasantness & 5.39 & 5.12 & - & $2 / 2$ & 1.551 & 0.213 \\
\hline
\end{tabular}


Finally, the constant version of intensity and pitch are removed so that a Student's $t$-test between fade-up vs fade-down intensity versions and ascending vs descending versions can be applied to see if effects may be more significant. As for the first binomial, Levene's homogeneity of variance test was statistically nonsignificant for the two variables. However, the Student's $t$-test applied to the binomial ascending vs descending pitch shows that Levene's homogeneity of variance test is statistically nonsignificant for pleasantness and significant for calmness/ excitement $(p>0.05)$, and the $t$-test significance does result in significant results for calmness/excitement $(t(880)=2.003$, $p<0.05)$, the descending pitch sonic logo being more exciting $(M=3.34)$ than the ascending pitch sonic logo $(M=3.03)$ (Table 4 presents all the means, SDs and significance).

\section{Discussion}

This study posed three hypotheses and three research questions on how acoustic features' variations (intensity, pitch and pace) can orient response and transmit brand personality traits when perceiving sonic logos of brands. The first $R Q$ and three hypotheses were posed to isolate effects of each of the acoustic features on psychophysiological responses. First, $R Q 1$ could not be answered as no combined variations among the three acoustic features were significantly associated with the orienting response. In addition, as reported, $H 1$ (effect of fade up intensity variations on orienting response) was not supported.

Noticeably, the significant decrease on EDA related with the fade-down intensity condition appears as counterintuitive at a first sight. Although there are mixed research findings, boredom has been associated in some cases to states of increased arousal (Elpidorou, 2018a; Elpidorou, 2018b). A putative explanation for this effect would thus be that the fadedown condition had reinforced the impression that the content would be boring, thus leading to the experience of subjective arousal (e.g. related to the frustration associated with boredom) and the subsequent increase on EDA. This is highly congruent with the fact that participants reported fade-up sonic logos to be more pleasant than the fade-down sonic logos; as well as the fact that EDA levels were increasing over time while the (quite repetitive) message was played. Finally, fade-down is usually processed as something going away or finishing, hence an increase in EDA can be easily attributed to the surfeit with the message. In this line of interpretation, the pattern of regularity or "goodness-of-form" is also associated with predictability, constancy and lack of change. A fade-down sonic logo clearly opposes these principles, even more if this fade-down is presented at first and the commercial message goes next. This irregular unpredictable pattern goes against calm and low arousal. Moreover, the use of intensity variations in media messages and advertising production is uncommon, as intensity levels are usually kept constant.

Regarding H2 (pitch variations), no clear pitch variations were associated with orienting response. There are several possible reasons for this. Although previous research with music (Chuen et al., 2016; Gomez and Danuser, 2007; Kellaris and Rice, 1993) or news presenters (Mas Manchón, 2011; Rodero, 2015) shows patterns of physiological responses similar to our hypothesis, it is possible that the magnitude of the changes in pitch in our sonic logos were not enough to elicit such patterns. Additionally, the short duration of the stimulus could have limited its impact. There is also the possibility that the number of stimuli lead to habituation on the physiological reactivity (cf. Dawson et al., 2007).

Evidence did support H3: fast-paced sonic logos did orient response as opposed to slow-paced sonic logos. This result is coincident with previous findings on the arousing effects of high-paced music (Chuen et al., 2016; Dillman Carpentier and Potter, 2007; Kim et al., 2019; van der Zwaag et al., 2011), which tend to be explained as a reaction of the motivational system to the threat/alert functionality of a potentially relevant or new element approaching fast (Bispham, 2009). The contribution of this study is clear as it has proven this mechanism in the case of the sonic logos processing. Furthermore, it may be the case that pace variations may act as a primer and mask the effects of intensity.

Research questions 2 and 3 connected acoustic features and self-reported measures. Regarding $R Q 2$, on the one hand, the method design was not suitable to measure how acoustic features may be associated with brand recognition. This variable was measured on a yes-no nominal scale with little statistical power and consistency considering the great amount of control variables and the need to repeat messages. On the other, the self-reported perception on calmness/excitement resulted in some significant outcomes. Remarkably, in line with the Gestalt-like theories about the relevance of musical patterns for perception, the composite "fade-up intensity and ascending-pitch" (arousing) sonic logos were perceived as more pleasant. Also, fast-paced sonic logos were perceived as more exciting and descending-pitch sonic logos were more pleasant as opposed to constant sonic logos. It seems contradictory that non-arousing sonic logos were perceived as exciting too, although main significant results are given by intensity and pitch's matching directions. The only constant version of sonic logo to give significant results was the perception of the constant pitch sonic logo as calm. However, the reported low significance of pitch-related findings leads researchers to focus on intensity and pace variations for practical implications.

Table 4 Student's $t$-test on emotions raised by the dichotomized sonic logo variations: ascending vs descending and fade up versus fade down

\begin{tabular}{lcccc}
\hline Dependent variables & $\boldsymbol{M}$ Intens. fade up & M Intens. fade down & SD & $\boldsymbol{F}$ \\
\hline Excitement & 3.20 & 3.26 & $2.1 / 2.1$ & 0.181 \\
Pleasantness & 5.29 & 5.08 & $2 / 1.95$ & 2.166 \\
Excitement & $M$ pitch ascending & $M$ pitch descending & SD & 0.671 \\
Pleasantness & 3.03 & 3.34 & $2.13 / 2$ & $F$ \\
\hline
\end{tabular}


Finally, regarding $R Q 3$, this research question focuses on whether sonic logos' acoustic features can be characterized by the 12 personality traits. The factor analysis applied to the brand personality data resulted in three different composites from Geuens et al.'s (2009) scale, which we named energy, balance and emotion. In addition, the one-way ANOVA, that was applied, showed no significant results for intensity, pitch and pace variations. Thus, no findings can be reported and discussed regarding $R Q 3$.

Overall, these findings should be interpreted and applied cautiously because of several here-reported non-significant relations and a few contradictions. However, in general, these findings build on the importance of combining features in a congruently shaped-background pattern to increase pleasantness. More specifically, fade-up intensity, fast and arousing features of sonic logos may help to improve processing fluency (Leder et al., 2004; Reber et al., 2004), especially considering that the sonic logo was placed at the beginning of the message. Furthermore, fast sonic logos elicited excitement too. Constant sonic logos elicited calmness although they had no psychophysiological effect in line with its conception as shape-less sound. Although this experiment did not test complexity and no significance can be attributed to personality traits, the pleasantness attributed to the pattern-like sonic logos as opposed to pattern-less sonic logos aligns with the perceptual abstraction explained by the RAF concept (Bonde and Hansen, 2013).

In sum, among the independent variables considered, the only one that is clearly associated with an increase in participants' attentional orientation (as indexed by a reduction on HR) is fast-paced sonic logos. If we add the self-reported results to the discussion, a broader picture is obtained. Fade-up arousing sonic logos tend to be considered as pleasant, whereas fade-down sonic logos tend to be considered as unpleasant. Slow and descending sonic logos are perceived as calmer, and no concluding remarks can be drawn from pitch variations' results.

\section{Conclusions}

This study has taken a psychophysiological approach, according to which acoustic features of sonic logos can be considered as melodic elements associated with motivation to process information, attention and the transmission of emotions. Accordingly, researchers have posited hypotheses and research questions on the orienting response and approach effect of fade up; the increase in excitement and relevance of ascending pitch and fast pace; and the potential transmission of emotions and personality values aligned with sound features. Remarkably, fast-paced sonic logos elicited orienting responses. Furthermore, this study found that pleasantness is associated with fade-up and arousing sonic logos. Although more research is needed, specifically regarding pitch variations, these results provide insights that point to the importance of brand values and emotions in sound messages, as well as the need to further test acoustic patterns associated with brands. This study is the first, to our knowledge, to try measuring orienting response to acoustic features of brands and the association of emotions and brand personality traits. In fact, this study has presented a rigorous innovative experimental design, with full control of variables, which could be improved in future studies, as will be discussed in the limitations and further research section.

The fact that arousing features in general (fade-up, increase in pitch and intensity and fast sonic logos) both orient response and are perceived as more pleasant (appetitive/approach mechanism), and the fact that constant pitch and slow sonic logos are perceived as calmer, reinforce the existence of two established patterns for brand recognition and processing. In line with the media psychology approach, first, the typical (pattern-like) arousing features may orient response because of the newness of information. Whereas, second, the non-arousing features were perceived as relevant for the perception of calmness. In a nutshell, fade-up intensity and fast tunes are the most suitable for the sonic logo to orient response and be perceived as pleasant; fade-down is not recommended ever, and slow tunes are relaxing.

\section{Implications for practice}

Findings in this study bring up two principal implications for practitioners (Table 5). First, when designing a sonic logo, practitioners should keep invariable two acoustic features that are important for the sonic logo to raise attention, to be processed as a unit and to be perceived as pleasant. Those stable acoustic features are named here as the "arousing template" and take the fade-up intensity and ascending pitch pattern. Upon this template, practitioners can make various strategic decisions in the branding field - making use of the significance/symbolism of instruments, the tonality of voices, the meaning of lyrics and the effects of sounding objects. Conversely, we are inclined to discard the use of fade-down intensity sonic logos, as fade-down entails that the sound vanishes progressively, which leads to boredom and tiredness (as attention also vanishes), giving great opportunities for any other natural or mediated stimuli to prevail.

Second, upon this general pattern, our study has provided evidence on how to manage the pace of sonic logos as a branding strategy. Practitioners may opt for either a brand identity/recognition strategy by using fast sonic logos or for a brand values/brand personality strategy by using slow sonic logos.

On the one hand, brand identity has traditionally been defined from a managerial standpoint, thus focusing on what identity features are made explicit in the organization's logo, the product's packaging design, naming, corporate colors, mission and vision statements, advertising and branding communications and so on and so forth. On the consumer end, the brand recognition construct entails the effective transmission of those features so that the consumer recognizes them as belonging to a certain brand. This study shows that a fast-paced sonic logo is a key feature to follow such a strategy, that is, a fast-paced sonic logo is a key feature for the organization to build on the brand's identity and raise the brand's recognition. The brand identity/recognition strategy can be most suitable for new brands, for brands entering new markets, for new sonic logos or for sonic logos played in saturated environments such as shopping malls with background noise, long commercial breaks or challenging processing situations such as multitasking or hard-working 
Table 5 Rationale, findings and implications on how acoustic features of sonic logos are associated with the orienting response and self-reported emotions

\begin{tabular}{|c|c|c|c|c|}
\hline Acoustic features & Hypothesis/RQ & Findings & Interpretation & Implications \\
\hline $\begin{array}{l}\text { Fade up } \\
\text { Fade down }\end{array}$ & $\begin{array}{l}\text { Orient response to the motivational } \\
\text { significance of distance and movement }\end{array}$ & $\begin{array}{l}\text { Pleasant } \\
\text { EDA component of the } \\
\text { orienting response. } \\
\text { Unpleasant }\end{array}$ & $\begin{array}{l}\text { Regular pattern } \\
\text { Boredom } \\
\text { Tiredness }\end{array}$ & $\begin{array}{l}\text { Recommended for all uses } \\
\text { Not recommended, especially not at the } \\
\text { beginning of the message }\end{array}$ \\
\hline $\begin{array}{l}\text { Ascending/ } \\
\text { descending/ } \\
\text { constant pitch }\end{array}$ & $\begin{array}{l}\text { Orient response to the motivational } \\
\text { significance of variation in the } \\
\text { appetitive/aversive system }\end{array}$ & No significant & $\begin{array}{l}\text { Complexity of the } \\
\text { design method }\end{array}$ & $\begin{array}{l}\text { Experimental designs focusing on pitch are } \\
\text { required }\end{array}$ \\
\hline $\begin{array}{l}\text { Constant } \\
\text { intensity and } \\
\text { pitch }\end{array}$ & $\begin{array}{l}\text { No motivated orienting response or } \\
\text { values transmissions }\end{array}$ & No significant & $\begin{array}{l}\text { Constancy denies } \\
\text { the very nature of } \\
\text { stimuli }\end{array}$ & Not recommended whatsoever \\
\hline Fast & $\begin{array}{l}\text { Orient response to the emotional } \\
\text { significance of pace: high arousal and } \\
\text { excitement }\end{array}$ & $\begin{array}{l}\text { Cardiac component of the } \\
\text { orienting response. } \\
\text { Exciting }\end{array}$ & $\begin{array}{l}\text { Enhanced } \\
\text { information intake }\end{array}$ & $\begin{array}{l}\text { Recommended in new or innovative SB } \\
\text { strategies and sonic logos }\end{array}$ \\
\hline Slow & Low arousal and passivity & $\begin{array}{l}\text { No orienting response. } \\
\text { Calm }\end{array}$ & $\begin{array}{l}\text { Relaxes and } \\
\text { transmits values }\end{array}$ & $\begin{array}{l}\text { Recommended in well-established sound } \\
\text { branding strategies and well-known sonic } \\
\text { logos }\end{array}$ \\
\hline Arousing & $\begin{array}{l}\text { Gestalt Theory, RAF, processing } \\
\text { fluency }\end{array}$ & $\begin{array}{l}\text { Pleasant. } \\
\text { Exciting }\end{array}$ & Form and regularity & Recommended for all uses \\
\hline Non-arousing & & No significant & No regular pattern & More research is required \\
\hline
\end{tabular}

hours. In all these instances, the recognition of the brand through a sonic brand identity is the main goal of the branding strategy.

On the other hand, the transmission and allocation of values and personality traits is typical for matured and sophisticated brands or for brands performing in more exclusive and interactive branding contexts. A brand personality strategy entails a complex process of weak anthropomorphism upon which consumers internalize some human personality traits as belonging to the brand. The specific transmission of brand values and the brand personality strategy would thus require a slow and exclusive processing such as this elicited from the slow-paced piano tunes of the Nespresso's sonic logo played in its boutiques. Similarly, Intel and McDonald's may opt for slower versions of their sonic logos to transmit such values in some contexts. Precisely, the brand values/brand personality strategy can be most suitable for well-known sonic logos or for sonic logos played in quiet environments, e.g. official stores or point of sales. This study shows that a slow-paced sonic logo is a key feature to follow such a strategy, that is, a slow-paced sonic logo is a key feature for the organization to build on the brand's personality traits, values' transmission and associations.

\section{Limitations and future research}

This study presents various limitations. Clearly, the use of sonic logos with no voice and a strict experimental control of variables made the study slightly bothersome for participants. In this regard, 18 sonic logos may be an excessive number of stimuli, thus driving them to fatigue and boredom. Closely related, the brand personality scale added complexity and increased the duration of the experiment. In addition, a yes/no brand recognition scale can only be tested in very simple and well-focused designs. In general, this study would benefit from implementing different experiments in several phases.

Furthermore, the sample of participants was composed of university students aged 19-22. These participants do not clearly represent an age cohort or the product's target; thus, it is a convenient sample based on the homogeneity of participants. Authors also admit the need to work with established validated scales of familiarity, even though this variable was used as a control variable in this study. However, in general, the independent and dependent variables applied, as well as the sonic logo and the materials produced (voices and message) are solid grounds to replicate the study in the future.

This study has covered important gaps of knowledge regarding the effects of music-based sonic logos; however, some important questions remain unanswered and, thus, a few gaps are now more noticeable. Pitch variations could be the only focus of a research, so that the number of experimental versions would be much lower. Hypotheses on the orienting response to pitch-ascension and to the various combinations of pitch and pace in sonic logos need to be tested. Further, future research should try to isolate acoustic variations of different sounds (effects, music and voice) when testing brand recognition, values and personality.

This is crucial field of study given the advent of portable or wearable ICTs and the Internet of things, along with the new forms of marketing, PR and branding practices. This scenario is bringing great opportunities for researchers to apply integrated methods (dynamic psychophysiological measures, observation, behavior and self-reported measures) and thus create evidence on how to raise attention, trigger sensory experiences and elicit information processing. 


\section{References}

ABA. Audio Branding Academy (2017), “Audio logo database", available at: http://audio-logo-database.com/ (accessed 10 November 2017).

Alpert, M.I., Alpert, J.I. and Maltz, E.N. (2005), "Purchase occasion influence on the role of music in advertising", Fournal of Business Research, Vol. 58 No. 3, pp. 369-376.

Babyak, M.A. (2004), "What you see may not be what you get: a brief, nontechnical introduction to overfitting in regression-type models", Psychosomatic Medicine, Vol. 66 No. 3, pp. 411-421.

Bach, D.R., Schächinger, H., Neuhoff, J.G., Esposito, F., Salle, F.D., Lehmann, C., Herdener, M., Seifritz, E. (2007), "Rising sound intensity: an intrinsic warning cue activating the amygdala", Cerebral Cortex, Vol. 18 No. 1, pp. 145-150.

Ballouli, K. and Heere, B. (2015), "Sonic branding in sport: a model for communicating Brand identity through musical fit", Sport Management Review, Vol. 18 No. 3, pp. 321-330.

Bispham, J. (2009), “Music's 'design features': musical motivation, musical pulse, and musical pitch", Musicae Scientiae, Vol. 13 No. 2_suppl, pp. 41-61.

Biswas, D., Lund, K. and Szocs, C. (2009), "Sounds like a healthy retail atmospheric strategy: effects of ambient music and background noise on food sales", fournal of the Academy of Marketing Science, Vol. 47, pp. 37-55.

Bliese, P. (2016), "A brief introduction to $\mathrm{R}$, the multilevel package and the nlme package", available at: https://cran.rproject.org/doc/contrib/Bliese_Multilevel.pdf

Bolls, P. (2013), "I can hear you, but can I see you? The use of visual cognition during exposure to high-imagery advertisements", Communication Research, Vol. 29 No. 5, pp. 537-563.

Bolls, P. and Lang, A. (2003), "I saw it on the radio: the allocation of attention to high-imagery radio advertisements", Media Psychology, Vol. 5 No. 1, pp. 33-55.

Bonde, A. and Hansen, A.G. (2013), "Audio logo recognition, reduced articulation and coding orientation: rudiments of quantitative research integrating branding theory, social semiotics and music psychology", SoundEffects - an Interdisciplinary fournal of Sound and Sound Experience, Vol. 3 Nos 1/2, pp. 112-135.

Bradley, M.M. (2009), "Natural selective attention: orienting and emotion", Psychophysiology, Vol. 46 No. 1, pp. 1-11.

Bradley, M.M. and Lang, P.J. (2007), "Emotion and motivation", in Cacioppo, J.T., Tassinary, L.G. and Berntson, G.G. (Eds), Handbook of Psychophysiology, Cambridge University Press, New York, NY, pp. 581-607.

Buss, D.M. (2008), Evolutionary Psychology: The New Science of the Mind, (3rd ed), Pearson Education, Boston.

Chuen, L., Sears, D. and McAdams, S. (2016), "Psychophysiological responses to auditory change", Psychophysiology, Vol. 53 No. 6, pp. 891-904.

Davis, D.D., Bagchi, R. and Block, L.G. (2016), “Alliteration alters: phonetic overlap in promotional messages influences evaluations and choice”, fournal of Retailing, Vol. 92 No. 1, pp. 1-12.

Dawson, M.E., Schell, A.M. and Filion, D.L. (2007), "The electrodermal system", in Cacioppo J.T., Tassinary L.G. and Berntson G.G. (Eds), Handbook of Psychophysiology, 3rd ed., Cambridge University Press, New York, NY, pp. 200-223.
Dillman Carpentier, F.R. and Potter, R.F. (2007), “Effects of music on physiological arousal: explorations into tempo and genre", Media Psychology, Vol. 10 No. 3, pp. 339-363.

Dubé, L., Chebat, J.C. and Morin, S. (1995), "The effects of background music on consumers' desire to affiliate on buyer- seller interactions", Psychology \& Marketing, Vol. 12 No. 4, pp. 305-319.

Elpidorou, A. (2018a), "The bored mind is a guiding mind: toward a regulatory theory of boredom", Phenomenology and the Cognitive Sciences, Vol. 17 No. 3, pp. 455-484.

Elpidorou, A. (2018b), "The good of boredom", Philosophical Psychology, Vol. 31 No. 3, pp. 323-351.

Gabrielsson, A. and Lindstrom, E. (2001), "The influence of musical structure on emotional expression", in Juslin, P. and Sloboda, J.A. (Eds), Music and Emotion: Theory and Research, Oxford University Press, New York, NY, pp. 223-248.

Geuens, M., Weijters, B. and De Wulf, K. (2009), "A new measure of brand personality", International fournal of Research in Marketing, Vol. 26 No. 2, pp. 97-107.

Gomez, P. and Danuser, B. (2007), "Relationships between musical structure and psychophysiological measures of emotion", Emotion, Vol. 7 No. 2, pp. 377-387.

Graakjær, N.J. and Bonde, A. (2018), "Non-musical sound branding - a conceptualization and research overview", European fournal of Marketing, Vol. 52 Nos 7/8, pp. 1505-1525.

Groves, J. (2009), "A short history of sound branding", in Bronner, K. and Hirt, R. (Eds), Audio Branding Brands, Sound and Communication, Reinhard Fischer, Baden-Baden, Germany, pp. 62-75.

Gustafsson, C. (2015), "Sonic branding: a consumer-oriented literature review", Fournal of Brand Management, Vol. 22 No. 1, pp. 20-37.

Jackson, D. (2004), Sonic Branding, Palgrave McMillan, New York, NY.

Kallinen, K. and Ravaja, N. (2003), "Emotion-related responses to audio news with rising versus falling background tone sequences”, Musicae Scientiae, Vol. 7 No. 1_suppl, pp. 85-110.

Kellaris, J.J. and Rice, R.C. (1993), "The influence of tempo, loudness, and gender of listener on responses to music", Psychology and Marketing, Vol. 10 No. 1, pp. 15-29.

Khalfa, S., Roy, M., Rainville, P., Dalla Bella, S. and Peretz, I. (2008), "Role of tempo entrainment in psychophysiological differentiation of happy and sad music?", International Fournal of Psychophysiology, Vol. 68 No. 1, pp. 17-26.

Kim, J., Strohbach, C.A. and Wedell, D.H. (2019), "Effects of manipulating the tempo of popular songs on behavioral and physiological responses”, Psychology of Music, Vol. 47 No. 3, pp. 392-406.

Klink, R.R. (2000), "Creating brand names with meaning: the use of sound symbolism", Marketing Letters, Vol. 11 No. 1, pp. 5-20.

Krishnan, V., Kellaris, J.J. and Aurand, T.W. (2012), "Sonic logos: can sound influence willingness to pay?", fournal of Product $\mathcal{E}$ Brand Management, Vol. 21 No. 4, pp. 275-284.

Kristjansson, S.D., Kircher, J.C. and Webb, A.K. (2007), "Multilevel models for repeated measures research designs in 
psychophysiology: an introduction to growth curve modeling", Psychophysiology, Vol. 44 No. 5, pp. 728-736.

Lang, A. (2009), "The limited capacity model of motivated media message processing", in Nabi, R.L. and Oliver, M.B. (Eds), The SAGE Handbook of Media Processes and Effects, SAGE Publications, Thousand Oaks, CA, pp. 193-204.

Lantos, G.P. and Craton, L.G. (2012), "Model of consumer response to advertising music", fournal of Consumer Marketing, Vol. 29 No. 1, pp. 22-42.

Leder, H., Belke, B., Oeberst, A. and Augustin, D. (2004), "A model of aesthetic appreciation and aesthetic judgments", British Fournal of Psychology, Vol. 95 No. 4, pp. 489-508.

Lehmann, M. (2008), "The voice in Brand sound", in Bronner, $\mathrm{K}$. and Hirt, R. (Eds), Audio Branding, Baden-Baden, Nomos Edition Reinhard Fischer, Germany, pp. 83-87.

Lowe, M.L. and Haws, K.L. (2017), "Sounds big: the effects of acoustic pitch on product perceptions", fournal of Marketing Research, Vol. 54 No. 2, pp. 331-346.

Lowe, M.L., Loveland, K.E. and Krishna, A. (2019), “A quiet disquiet: anxiety and risk avoidance due to nonconscious auditory priming", fournal of Consumer Research, Vol. 46 No. 1, pp. 159-179.

Mas Manchón, L. (2011), "Modelo superestructural de la noticia en televisión", Estudios Sobre El Mensaje Periodístico, Vol. 17 No. 1, pp. 95-116.

Mas Manchón, L. (2011), "The intensity of the tv spoken news", Estudios de Fonética Experimental, No. 20, pp. 71-112.

Moosmayer, D. and Melan, M. (2010), "The impact of sound logos on consumer brand evaluation", Enhancing Knowledge Development in Marketing, No. Vol. 28, pp. 1-22.

Müller, J. and Kirchgeorg, M. (2010), "Audio branding in line with brand personality”, Audio Branding Academy Yearbook, pp. 189-201.

Müller, J. and Kirchgeorg, M. (2011), "Emotional audio branding in a retailing setting", Audio Branding Academy Yearbook, pp. 161-169.

North, A.C., MacKenzie, L.C., Law, R.M. and Hargreaves, D.J. (2004), "The effects of musical and voice 'fit' on responses to advertisements", Fournal of Applied Social Psychology, Vol. 34 No. 8, pp. 1675-1708.

Page-Gould, E. (2017), "Multilevel modeling”, in Cacioppo, J.T., Tassinary, L.G. and Berntson, G.G. (Eds), Handbook of Psychophysiology, Cambridge University Press, New York, NY, pp. 628-661.

Patel, A.D. (2010), "Music, biological evolution, and the brain", in Bailar, M. (Ed.), Emerging Disciplines, Rice University Press, Houston, TX, pp. 91-144.

Pathak, A., Velasco, C. and Spence, C. (2020), "The sound of branding: an analysis of the initial phonemes of popular brand names", fournal of Brand Management, Vol. 27 No. 3, pp. 339-354.

Potter, R.F. (2006), "Made you listen: the effects of production effects on automatic attention to short radio promotional announcements", fournal of Promotion Management, Vol. 12 No. 2, pp. 35-48.

Potter, R.F. and Bolls, P.D. (2012), Psychophysiological Measurement and Meaning: Cognitive and Emotional Processing of Media, Routledge, New York, NY.

Potter, R.F., Lang, A. and Bolls, P.D. (2008), "Identifying structural features of audio: orienting responses during radio messages and their impact on recognition", fournal of Media Pscyhology, Vol. 20 No. 4, pp. 169-178.

Potter, R.F., Lynch, T. and Kraus, A. (2015), "I've heard that before: habituation of the orienting response follows repeated presentation of auditory structural features in radio", Communication Monographs, Vol. 82 No. 3, pp. 359-378.

Reber, R., Schwarz, N. and Winkielman, P. (2004), "Processing fluency and aesthetic pleasure: is beauty in the perceiver's processing experience?", Personality and Social Psychology Review, Vol. 8 No. 4, pp. 364-382.

Rodero, E. (2015), "The spark orientation effect for improving attention and recall", Communication Research, Vol. 46 No. 7, pp. $965-985$.

Rodero, E. (2019a), "Do your ads talk too fast to your audio audience? How speech rates of audio commercials influence cognitive and physiological outcomes", fournal of Advertising Reseach, Online First, doi: 10.2501/JAR-2019-038.

Rodero, E. (2019b), "The spark orientation effect for improving attention and recall", Communication Research, Vol. 46 No. 7, pp. 965-985.

Rodero, E. and Larrea, O. (2021), “Audio design in branding and advertising", in Mas, Ll. (Ed.), Innovation in Advertising and Branding Communication, Routledge, New York, NY, pp. 69-85.

Rodero, E. and Mas, L. (2020), “Audio experience”, in Filimowicz, M. and Tzankova, V. (Eds), Reimagining Communication. Experience, Routledge, New York, NY and London, pp. 32-46.

Rodero, E., Larrea, O. and Vázquez, M. (2013), "Male and female voices in commercials. Analysis of effectiveness, adequacy for product, attention and recall", Sex Roles, Vol. 68 Nos 5/6, pp. 349-362.

Schmitt, B. (2012), "The consumer psychology of brands", Fournal of Consumer Psychology, Vol. 22 No. 1, pp. 7-17.

Van der Zwaag, M.D., Westerink, J.H. and van den Broek, E.L. (2011), "Emotional and psychophysiological responses to tempo, mode, and percussiveness", Musicae Scientiae, Vol. 15 No. 2, pp. 250-269.

Volker, B. and Milton, S. (2019), "Why sound and voice are the future on brand experience. Muse by Clio", available at: https://musebycl.io/music/why-sound-and-voice-are-futurebrand-experience (accessed 20 April 2020).

Winkler, I., Denham, S.L. and Nelken, I. (2009), "Modeling the auditory scene: predictive regularity representations and perceptual objects", Trends in Cognitive Sciences, Vol. 13 No. 12, pp. 532-540.

Yarkoni, T. and Westfall, J. (2017), "Choosing prediction over explanation in psychology: lessons from machine learning", Perspectives on Psychological Science, Vol. 12 No. 6, pp. 1100-1122.

Zampini, M. and Spence, C. (2005), "Modifying the multisensory perception of a carbonated beverage using auditory cues", Food Quality and Preference, Vol. 16 No. 7, pp. 632-641.

Zander, M.F. (2006), "Musical influences in advertising: how music modifies first impressions of product endorsers and brands", Psychology of Music, Vol. 34 No. 4, pp. 465-480.

Zentner, M., Grandjean, D. and Scherer, K.R. (2008), "Emotions evoked by the sound of music: characterization, classification, and measurement", Emotion, Vol. 8 No. 4, pp. 494-521. 


\section{Further reading}

Aaker, J. (1997), "Dimensions of brand personality", fournal of Marketing Research, Vol. 34 No. 3, pp. 347-335.

\section{About the authors}

Lluis Mas (37) is Professor in the Communication Department of UPF (Barcelona, Spain). His main research interests are branding, digital media, political communication, advertising, models of communication and physicophysiological measures. Dr Mas recently gained scholarship to visit Texas Tech University (June to November 2017), where he has developed a project on Sound Branding. Lluis Mas has been the coordinator of the "Communication, Advertising and Society" research group (CAS, UPF, www.upf.cas.edu), is the Head of Studies of the Advertising and PR undergraduate program at UPF and is currently chairing the Advertising Research ECREA TWG. Lluis Mas is the corresponding author and can be contacted at: lluis.mas@upf.edu

Paul Bolls is one of the leading researchers who apply the Media Psychophysiology paradigm to studying how individuals mentally process and respond to media content and technology. His research interests span a wide range of media content and technological platforms. He has conducted experiments on health communication, advertising, news, political communication, gaming, entertainment and digital/ interactive media. Dr Bolls directs Media Mind Insights, a research group dedicated to studying how the human mind processes and is influenced by media and regularly conducts Neuromarketing tests for large industry clients.

Emma Rodero is Researcher and Professor in the Department of Communication at Pompeu Fabra University (Spain), $\mathrm{PhD}$ in Communication, $\mathrm{PhD}$ in Psychology, Master in Pathology of Voice and Master in Psychology of Cognition. She obtained Marie Curie fellowship (European Union) to conduct research in the USA about cognitive processing of audio messages using psychophysiological techniques. She is the author of more than 12 books and 70 scientific papers about voice, radio and sound. She has over a decade of experience in the radio industry. She is currently a voice-over artist and has received awards for some radio dramas.

Miguel Barreda-Ángelesm holds a $\mathrm{PhD}$ in Social Communication (Pompeu Fabra University, 2014) and is Researcher within the Data Science \& Big Data Analytics unit at Eurecat. His research focuses on the analysis of the cognitive and emotional processing of new media technologies and their impact on users. He grounds on a multimodal approach combining the use of self-reported, behavioral and, particularly, psychophysiological methods.

Ashley Churchill studies Media Psychophysiology and Human-Computer Interaction as a master's student at Texas Tech University. She has worked in the Media Mind Insights lab under Dr Paul Bolls since 2016, where she contributes to both academic and industry media psychophysiology research.

For instructions on how to order reprints of this article, please visit our website:

www.emeraldgrouppublishing.com/licensing/reprints.htm

Or contact us for further details: permissions@emeraldinsight.com 